\title{
LASERTERAPIA NO TRATAMENTO DE LESÕES: SÉRIE DE CASOS
}

\section{ARTIGO ORIGINAL}

KASHIWABARA, Tatiliana Geralda Bacelar ${ }^{1}$

SAMPAIO, Débora de Oliveira ${ }^{2}$

OLIVEIRA, Bruna Evellyn Freitas de ${ }^{3}$

KASHIWABARA, Tatiliana Geralda Bacelar. SAMPAIO, Débora de Oliveira. OLIVEIRA, Bruna Evellyn Freitas de. Laserterapia no tratamento de lesões: Série de casos. Revista Científica Multidisciplinar Núcleo do Conhecimento. Ano 05, Ed. 03, Vol. 12, pp. 104-112. Março de 2020. ISSN: 2448-0959, Link de acesso: https://www.nucleodoconhecimento.com.br/saude/tratamento-de-lesoes

\section{RESUMO}

As feridas cutâneas, principalmente as de caráter crônico, acarretam consequências negativas para a qualidade de vida do portador, além do mais, representam um grave problema de saúde, uma vez que, a perda da integridade da pele facilita a proliferação de germes com potencial infeccioso. A terapia com laser de baixa potência tem sido utilizada com o propósito de promover a reparação tecidual, assim como redução da dor e melhor resposta aos processos inflamatórios. Nesse artigo, relata-se uma série

\footnotetext{
${ }_{1}^{1}$ Doutora em Administração pela Universidade Federal do Rio de Janeiro, Especialista em Alergia e Imunologia, Dermatologia e Pediatria. Professora titular de Pediatria no Instituto Metropolitano de Ensino Superior.

2 Acadêmica do sexto ano de graduação do curso de Medicina no Instituto Metropolitano de Ensino Superior.

3 Acadêmica do sexto ano de graduação do curso de Medicina no Instituto Metropolitano de Ensino Superior.
} 
de casos onde foi empregado o laser de baixa potência como terapia em feridas ulcerosas crônicas e estomatite herpética, com boa evolução clínica até o presente.

Palavras Chave: Laserterapia, laser de baixa potência, reparação tecidual, bioestimulação luminosa, úlceras.

\section{INTRODUÇÃO}

O laser (ligh amplification by stimulated emission of radiation) é uma radiação eletromagnética, fonte de luz monocromática, colimada e intensa. Pensado por Albert Einstein em 1917, que propôs princípios físicos da emissão estimulada. Hoje as aplicações desta tecnologia variam desde engenharia à medicina, uma vez que, pode ser utilizado para promover bioestimulação celular ${ }^{1}$.

Os lasers podem ser divididos em alta e baixa potência, sendo o primeiro, utilizado para cirurgias com a função de coagulação e corte de tecidos. Já o segundo, geralmente são aplicados com o intuito de reparação tecidual ${ }^{2}$.

A terapia com laser tem sido administrada para melhoria de processos inflamatórios com redução do edema e analgesia, promovendo uma melhora da qualidade de vida dos pacientes acometidos por injúrias diversas, como lesões decorrentes de candidíase, nevralgia, herpes, mucosite pós-quimioterapia ou radioterapia, estomatite aftosa, úlceras de pressão e até mesmo no tratamento de queimaduras ${ }^{3}$.

Estudos têm demonstrado que a bioestimulação luminosa de baixa frequência pode auxiliar no processo de regeneração tecidual por estimular a proliferação fibroblastos, queratinócitos, células uroteliais e endoteliais, mioblastos, a atividade antiinflamatória, síntese de colágeno e aumento da expressão de fatores de crescimento e citocinas ${ }^{4}$.

É de conhecimento que os resultados da terapia de baixa potência dependem de variáveis como comprimento de onda do laser, potência, dose e tempo aplicados. Os efeitos terapêuticos podem ser alcançados através de comprimentos de onda entre 600 e $1000 \mathrm{~nm}$, com potências de $1 \mathrm{~mW}$ a $5 \mathrm{~W} / \mathrm{cm}^{2}$. 


\section{MÉTODOS}

O laser foi aplicado em três pacientes nos seguintes parâmetros: laser com o comprimento de onda de 620 a $750 \mathrm{~nm}$, luz vermelha, emissão contínua, 15 segundos por ponto.

\section{RELATO DE CASO 1}

Paciente feminina, 81 anos, leucoderma, hipertensa e dislipidêmica, com histórico de queimaduras por água quente extensas em região dorsal, com 40 anos de evolução, de difícil cicatrização. Já haviam sido realizadas duas biópsias, sem alterações sugestivas de malignidade. A paciente realizou tratamentos com papaína, propionato de clobetasol, sulfadiazia, entre outros, sem apresentar remissão do quadro. No momento anterior ao início da laserterapia, estava em uso de neomicina, colagenase, rifocina spray, óleo de girassol e soro fisiológico $0,9 \%$ para higienização da lesão. Os medicamentos supracitados foram mantidos e iniciou-se a aplicação semanal do laser de baixa frequência, com duração de 15 segundos em cada lesão, por um mês. Notou-se nesse período, diminuição da dor, extensão e profundidade das lesões, como demonstrado na figura 1. 
Figura 1: úlcera em região dorsal com melhora da cicatrização após quatro sessões de laserterapia com intervalo de sete dias.
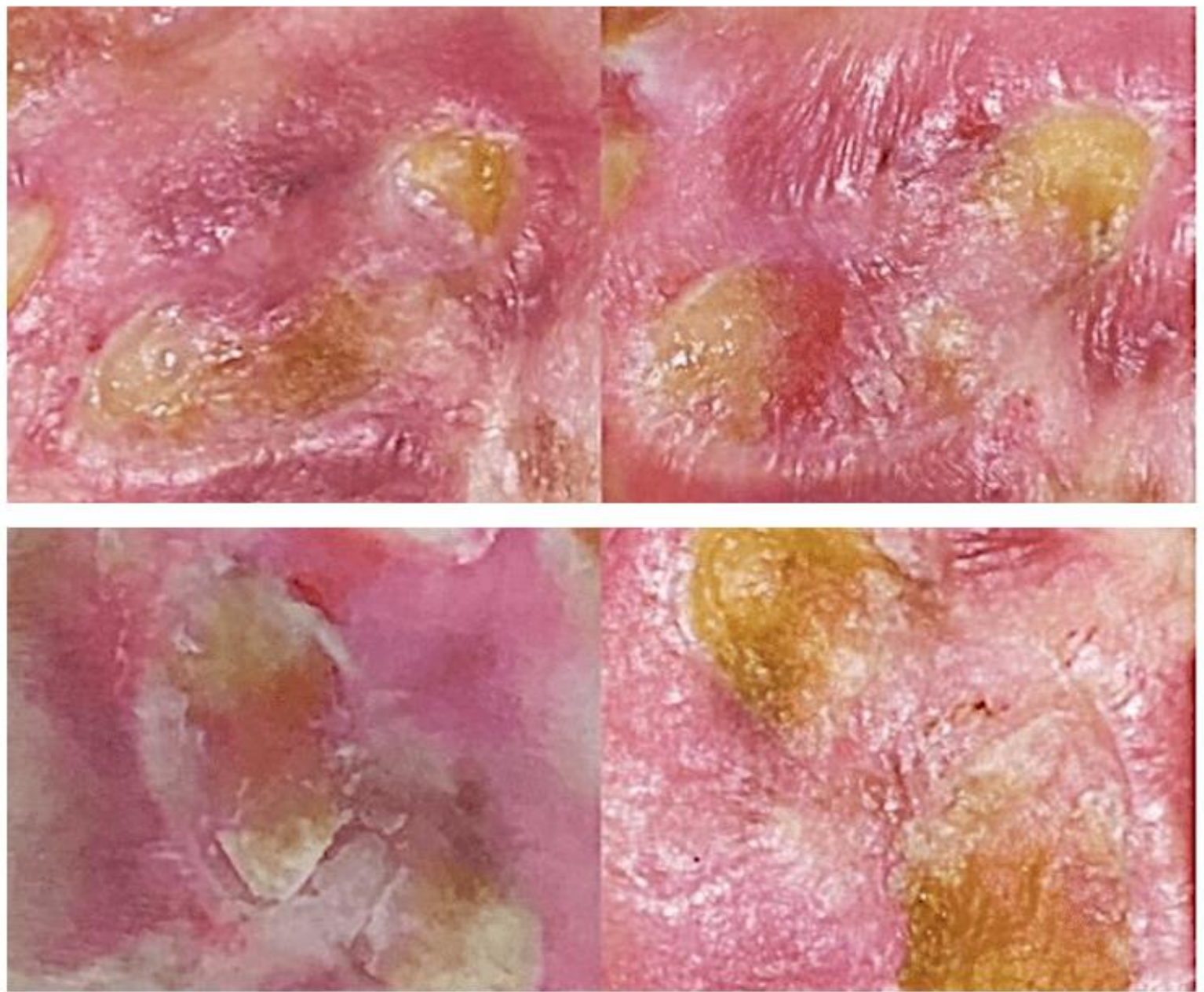

Fonte: arquivo pessoal

\section{RELATO DE CASO 2}

Paciente do sexo feminino, 22 anos, apresentava pequena lesão superficial de formato arredondado, coloração central branco-amarelada e contorno avermelhado, localizada na base da gengiva inferior ao canino direito, compatível com estomatite aftosa. Queixava-se de dor intensa que incapacitava o processo de mastigação.

Foi então irradiada com laser de baixa potência durante 15 segundos, uma vez ao dia, durante três dias, a superfície da lesão. 
No primeiro dia de aplicação, paciente relatou redução significativa da dor, retornando aos hábitos alimentares. No dia posterior, paciente afirmou analgesia completa do local, referindo-se dor leve apenas à manipulação do lábio inferior. Já no terceiro dia houve remissão completa da estomatite aftosa, como foi exemplificado em figura 2.

Figura 2: primeira imagem demonstra o primeiro dia de aplicação da laserterapia e segunda imagem o terceiro dia, já com melhora significativa da hiperemia e redução da lesão.
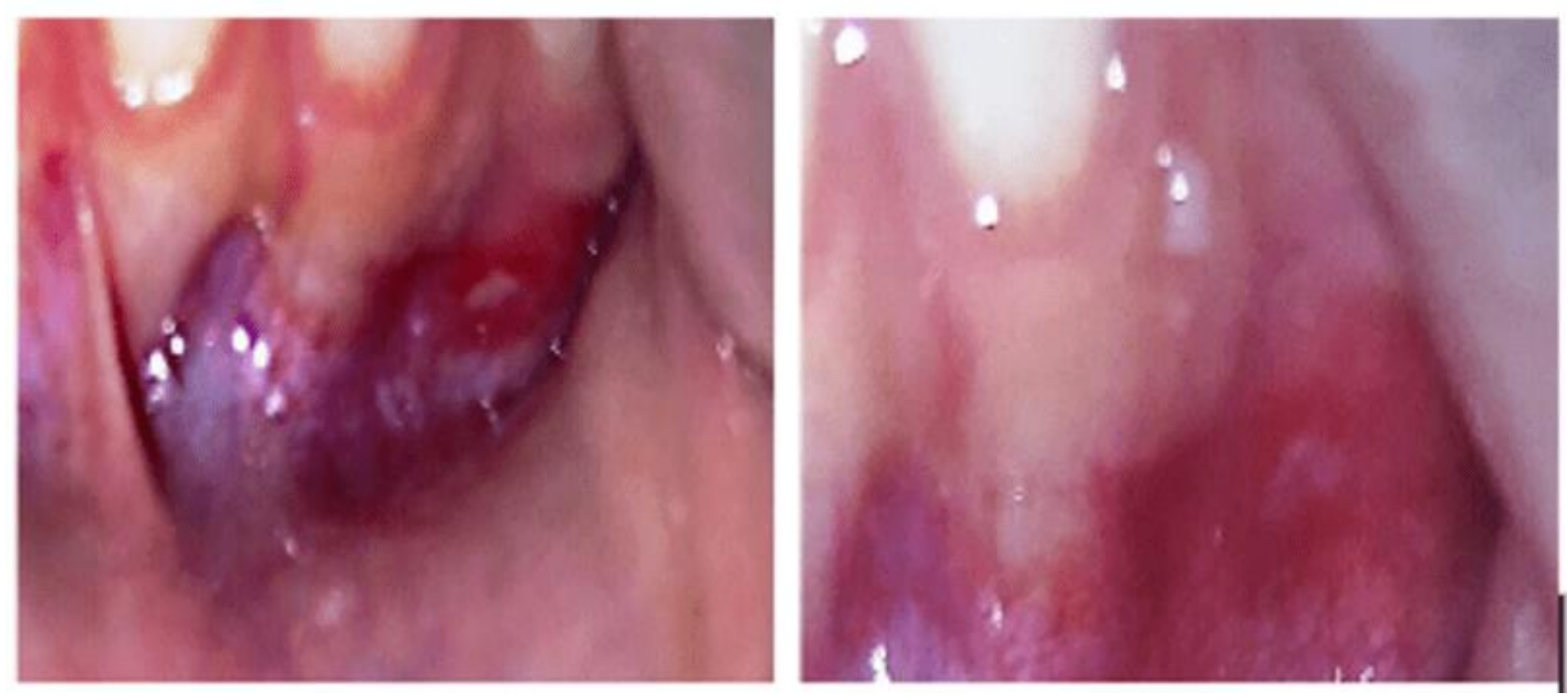

Fonte: arquivo pessoal

\section{RELATO DE CASO 3}

Paciente do sexo masculino, 54 anos, portador de lesão ulcerosa em região maleolar em membro inferior direito. Refere realização anterior de tratamentos medicamentosos, sem resultados significativos na cicatrização local. Também no período de um mês, foram realizadas aplicações semanais de laser de baixa frequência, com duração de 15 segundos. Em uma semana de aplicação, houve melhora significativa da lesão, todavia, ocorreu abandono do tratamento pela parte do paciente, sem justificativas. 
Figura 3: imagem mostra, em ordem cronológica, a evolução em cada semana do tratamento com laserterapia de baixa potência.

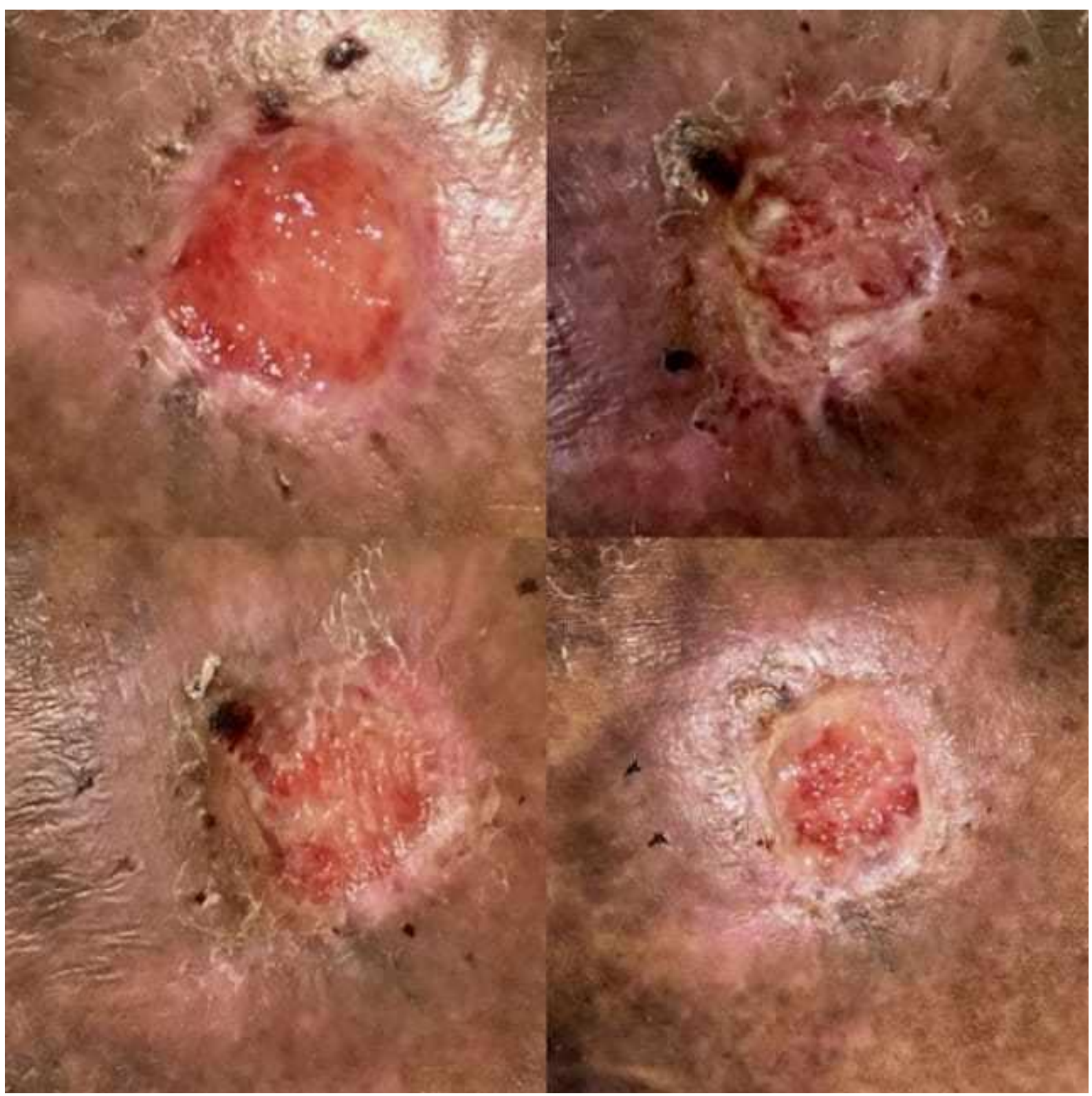

Fonte: arquivo pessoal

\section{DISCUSSÃO}

Para que a laserterapia seja efetiva, o tecido deverá absorver a luz e isso somente é possível através de cromóforos, que são moléculas com tal capacidade. Dentre os exemplos dessas células estão a oxihemoglobina, melanina e a água. Quando 
a laserterapia é usada no espectro eletromagnético visível, existe uma fotobioestimulação inicial na mitocôndria que ativa uma cadeia de eventos biológicos. O efeito fotoquímico ocorre pela absorção da luz pelos citocromos-oxidase e flavoproteínas causando oxidação de NAD, com consequente aumento da produção de ATP endocelular e alteração do potencial de membrana, favorecendo assim, a normalização das funções teciduais ${ }^{5,6,7}$.

Através dessas reações bioquímicas e fotofísicas, há estimulação mitocondrial, desencadeando proliferação de fibroblastos no epitélio. Há também a produção de colágeno e elastina que provoca retração da ferida, aumento de fagocitose e ativação de linfócitos, favorecendo a cicatrização. Uma vez que o ponto luminoso não só atinge a área específica da lesão como também o tecido adjacente, o laser promove a prevenção de possíveis lesões ${ }^{3,2}$.

As úlceras podem ser definidas como lesões localizadas, que acometem pele e tecidos subjacentes, usualmente sobre proeminências ósseas, resultantes de pressão, ou pressão associada a cisalhamento e/ou fricção. Estas causam significante impacto social e econômico devido à natureza recorrente e ao longo tempo decorrido entre sua abertura e cicatrização. Além de perdas financeiras, com tratamentos não efetivos, o problema traz também, transtornos psicológicos e impedem ou dificultam a participação do indivíduo em programas de reabilitação. Dessa forma, a prevenção e tratamento no estágio inicial devem ser a meta da assistência que vise à qualidade. Já as Lesões provenientes da estomatite aftosa são de aspecto arredondado, com borda eritematosa e muito dolorosa. Geralmente, acomete o paciente diversas vezes ao ano e tem duração aproximada de 14 dias, sem o tratamento adequado ${ }^{8,9,10}$.

A laserterapia de baixa intensidade também tem sido empregada com frequência e há resultados que inferem melhora no desempenho, nos praticantes de atividade física, visando recuperação muscular após atividade e prevenção de lesões. (Foi realizado um estudo comparando os efeitos da laserterapia de baixa intensidade vermelha $660 \mathrm{~nm}$ ) e infravermelha (830 nm) na prevenção de fadiga em indivíduos saudáveis e foi visto que ambos são efetivos no retardo do desenvolvimento da mesma e aumento do desempenho muscular ${ }^{11}$. É importante salientar que a resposta à laserterapia 
depende não só da característica da luz utilizada, mas também tipo de lesão, idade e cor da pele do paciente ${ }^{12}$. Os efeitos adversos da terapia são incomuns. Quando vistos, podem se apresentar como dor, edema, eritema e prurido no local da aplicação. Usualmente, são transitórios e não necessitam de tratamento adjuvante. Alterações locais de pigmentação podem ser vistas, principalmente em melanodermos e são irreversíveis ${ }^{13}$.

Até o momento, não há contraindicações absolutas à terapia com laser, no entanto, na presença de infecção ativa no sítio da lesão é recomendado efetuar antibioticoterapia previamente. Pacientes com história de infecção de repetição pelo herpes vírus simples, é prudente realizar o tratamento profilático com antiretroviral 14,15 .

\section{CONCLUSÃO}

Atualmente, observa-se uma tendência à incorporação de métodos menos invasivos e com poucos efeitos colaterais na tentativa analgesia e melhora na qualidade de vida desses pacientes. O laser terapêutico ou fototerapia com laser de baixa intensidade possui uma série de indicações e pode ser utilizada de forma isolada ou como coadjuvante de outros tratamentos.

A laserterapia quando comparada à ação dos medicamentos na terapêutica, apresenta ação minimamente invasiva, além do mais, destaca-se seu excelente custobenefício e fácil manuseio, constituindo assim, um importante arma terapêutica para o tratamento de tais enfermidades.

\section{REFERÊNCIAS}

1. F. F; OLIVEIRA, E. L. P; BARBOSA, F. S. B; SILVA, J. G. Low-level laser therapy in the expression of collagen after muscular surgical injury. Fisioterapia e Pesquisa, São Paulo, Vol.18, N.1, pag. 37-42, jan/mar., 2011. Disponível em: http://www.scielo.br/pdf/fp/v18n1/07.pdf. Acesso em: 15 out. 2017. 
2. ANDRADE, F. S. S; CLARK, R.M.O; FERREIRA M.L. Efeitos da laserterapia de baixa potência na cicatrização de feridas cutâneas. Col. Bras. Cir. Vol. $41 \mathrm{~N}$. 2, pag. 129-133. 2014. Disponível em: http://www.scielo.br/pdf/rcbc/v41n2/pt_0100-6991-rcbc-41-02-00129.pdf. Acesso em 15 jun. 2017.

3. REOLON, L. Z. et al. Impact Of Laser Therapy On Quality Of Life Of Cancer Patients With Oral Mucositis. Rev Odontol UNES., São Paulo, outubro, 2016. Disponível em: <http://www.scielo.br/pdf/rounesp/2017nahead/1807-2577rounesp-1807-257709116.pdf>. Acesso em 10 de jul, 2017.

4. HECKLER, M. C. T; BARBERINI, D. J; AMORIM, R. M. Low level laser therapy on cell cultures. Jornal Brasileiro de Ciência Animal 2014. Disponível em: http://www.jbca.com.br/v7n14/material_2014/efeitos_do_raio_laser_sobre_o_ cultivo_de_diferentes_tipos_celulares.pdf. Acesso em: 27 out. 2017.

5. HRUZA, G. J., TANZI, E. L. Laserterapia. Elsevier Health Sciences, Vol 1, p. 58-69, 2018. Disponível em: < ISBN: 9788491133117>

6. HENRIQUES, A. C. G.; CAZAL, C.; CASTRO, J. F. L. Low intensity laser therapy effects on cell proliferation and differentiation. Review of the literature. Col. Bras. Cir., Rio de Janeiro Vol.37, n.4, July/Aug., 2010. Disponível em: http://www.scielo.br/scielo.php?script=sci_arttext\&pid=S010069912010000400011

7. MenEGuZZO, D. T; BAVARESCO, T. LUCENA, A. F. Resultados da laserterapia em pacientes com feridas crônicas. Disponível em: http://www.lume.ufrgs.br/bitstream/handle/10183/163252/001024352.pdf?seq uence=1. Acesso em: 27. Out 2017.

8. WADA, A.; NETO, N.T.; FERREIRA, M.C. Úlceras por pressão. Revista de Medicina 89, n. 3, 2010.

9. NOGUEIRA, P.C.; CALIRI, M.H.L.; HAAS, V.J. Perfil de pacientes com lesão traumática da medula espinhal e ocorrência de úlcera de pressão em um hospital universitário. Revista Latino-americana de Enfermagem, v.14, n.3, p.372-377, Mai 2006. 
10. BRICE, S. Recurrent aphthous stomatitis. UptoDate, set. 2017. Disponível em: https://www.uptodate.com/contents/recurrent-aphthous-stomatitis. Acesso em: 09 abr. 2019.

11. OLIVEIRA, B. F; ROCHA, G. G; NETO, L. S. S; MATHEUS, J. P. C. M; MARTINS, E. F. Laser terapêutico de baixa intensidade na otimização e performance do movimento humano. Acta Brasileira do Movimento Humano. Vol.4, N.1, pag.52-60, janlmar., 2014. Disponível em: http://www.periodicos.ulbra.br/index.php/actabrasileira/article/view/2866/2135. Acesso em: 29 out. 2017.

12. KELLY, K.M. Laser and light therapy for cutaneous vascular lesions. UptoDate, abr. 2018. Disponível em: https://www.uptodate.com/contents/laser-and-lighttherapy-for-cutaneous-vascular-lesions. Acesso em: 09 mar. 2019.

13.SCOVELL, S. Laser and light therapy of lower extremity telangiectasias, reticular veins, and small varicose veins. UptoDate, mar. 2019. Disponível em: https://www.uptodate.com/contents/laser-and-light-therapy-of-lower-extremitytelangiectasias-reticular-veins-and-small-varicose-veins. Acesso em: 20 abr. 2019.

14. HULTMAN, S; YOSHIDA S. Laser therapy for hypertrophic scars and keloids. UptoDate, mar. 2019.2 Disponível em: https://www.uptodate.com/contents/laser-therapy-for-hypertrophic-scars-andkeloids. Acesso em: 06 abr. 2019.

Enviado: Setembro, 2019.

Aprovado: Março, 2020. 